\title{
Improving Surface Properties of Inconel 600 Alloy by Electroless Ni-P Deposition
}

\author{
Hassan. H. Masallb ${ }^{a *}$, Kadhim F. Al-Sultani ${ }^{a}$, Abdul Raheem. K. Abid Ali ${ }^{a}$ \\ ${ }^{a}$ College of Materials Engineering, University of Babylon, Hilla, Iraq
}

\author{
A R T I C LE INFO \\ Article history: \\ Received 18 November 2019 \\ Received in revised form 22 October 2019 \\ Accepted 30 October 2019
}

\section{Keywords:}

Electroless Plating

Ni-P

X-ray diffraction

Inconel 600

Tafel Extrapolation

\begin{abstract}
A B S T R A C T
The use of electroless Ni-P plating (EN) coating has attracted a surprising interest in the most recent years. Many useful characteristics of the electroless-plating method have created many benefits in different industries such as oil, gas, electronic, automotive, aerospace, and chemical. Some of the highlighted properties of such a method are superior corrosion resistance, superior mechanical properties, and uniform thickness of the coating as well as good surface finish properties, good adhesion characteristics, and a wide range of thickness. In this paper, electroless plating has been applied in a (Ni-P) bath at two different times of 2 and $3 \mathrm{hr}$ respectively. After the plating, a heat treatment at $400{ }^{\circ} \mathrm{C}$ for an hour under vacuum 10-4 torr has been done. The prepared samples were characterized by energy dispersive spectroscopy, X-ray diffraction, and scanning electron microscopy (SEM). In addition, micro-hardness and corrosion rate following Tafel extrapolation in two acidic solutions (1M HCl and $1 \mathrm{M} \mathrm{H} 2 \mathrm{SO} 4)$ were also determined. Vickers hardness values for specimens, coated by $\mathrm{Ni}-\mathrm{P}$ at 2 and $3 \mathrm{hr}$ have increased by $47 \%$ and $32 \%$ respectively. X-ray diffraction analysis for the coated surfaces showed two phases of Ni3P and NiP, presented before and after heat treatment. The SEM images of the cross sectional coated specimens revealed that the thickness of the coating is 68.43 and $92.71 \mu \mathrm{m}$ for 2 and $3 \mathrm{hr}$ coating time, respectively. Tafel analysis showed that the coated specimens had a lower corrosion current density compared to that for the bare specimens. The corrosion current density for the coated specimens in 1M H2SO4 increased by $57 \%$ with $2 \mathrm{hr}$ and $69 \%$ at $3 \mathrm{hr}$ coating time. While, the corrosion current density for the coated specimens in $1 \mathrm{M} \mathrm{HCl}$ increased by $37 \%$ and $83 \%$ at 2 and $3 \mathrm{hr}$ coating time respectively.
\end{abstract}

\section{Introduction}

Generally, deposition of Electroless nickel-phosphorus has been examined since it was initially described by Brenner and Riddell in 1946 [1]. The electroless $\mathrm{Ni}-\mathrm{P}$ alloys are commonly used in different engineering applications for their typical mechanical and physical properties such as excellent wear, abrasion and corrosion resistance, ductility, soldering, lubrication, and electrical properties as well as low cost of material [2,3]. Among the electro-plating techniques, electroless deposition has more advantages due to its low equipment cost, simple in operation, and the formation ability of very thin and uniform coating on both conductive and non-conductive surfaces. [4-6].

* Corresponding author.

E-mail address: hassanmaslab77@gmail.com (Hassan. H. Masallb) 
Various researchers had studied the electroless plating by (Ni-P) on various substrates. For example, Yeh, M. S. et.al [7] studied the electroless plating of nickel-phosphorous on nickel-base alloy (Inconel 718) with dimensions of $34 \times 15 \times 1.3 \mathrm{~mm}$. The aim of this study is to promote the diffusion bonding between two overlap surfaces and to reduce the undesirable intermediate components. The results showed that the shear strength of overlap diffusion bonding before coating by nickel-phosphor was $41.5 \mathrm{MPa}$ but it equal to $70.4 \mathrm{MPa}$ after coating. Osifuye et.al [8] investigated the effect of several parameters of the Ni-P electroless plating on carbon steel AISI 1045 substrate. Different parameters were considered i.e., bath concentrations, temperature, and time of deposition. The researcher employed $0.7-0.4 \mathrm{~g} / \mathrm{L}$ for $\mathrm{Ni}^{2+}$ while the other components stayed constant. The working temperature was variable and ranged from $70-100{ }^{\circ} \mathrm{C}$ and the plating time was 15 minutes and 35 minutes. It was noticed that the bath concentration of $0.5-0.6 \mathrm{~g} / \mathrm{L}$ at $25-35$ minutes and 80 ${ }^{\circ} \mathrm{C}$ gave a bright uniform film. It was also noticed that the bright deposition of Nickel at 25 minutes along with increasing coating time led to an increase in the amount of deposition per unit area. This was referred to the increase in wear resistance and the corrosion resistance. Entesar Sattar [9] studied the electroless plating of Ni-P reinforced by silicon carbide ( $\mathrm{SiC}$ ) on a low carbon steel substrate. The reinforcement was carried out by two different sizes of SiC particles $(11.2 \mu \mathrm{m}$ and $40 \mathrm{~nm})$. Several tests were carried out such as optical microscope, X-ray diffraction, hardness measurement, wear, scanning electron microscopy, and corrosion test. The hardness of the substrate was $230 \mathrm{HV}$ while the hardness of coating that contained $\mathrm{SiC}$ nanoparticle with $40 \mathrm{~nm}$ size increased by 5.2 times higher than the uncoated of base metal after the heat treatment at $400{ }^{\circ} \mathrm{C}$ for one hour. On the other hand the hardness measurement for Ni-P which strengthened by particles of silicon carbide with size $11.2 \mu \mathrm{m}$ increased by 3.8 times higher than the base metal after heat treatment at $400{ }^{\circ} \mathrm{C}$ for an hour. Kari Basavaraja [10] studied the electroless plating of Ni-P on medium carbon steel (C-40) substrate. The researcher chose several parameters such as sodium hypophosphite, $\mathrm{pH}$, and temperature. Chloride nickel was the source of metal ions and sodium hypophosphite was a reducing agent. The thickness of the coating was $10-15 \mu \mathrm{m}$ at 60 minutes and the hardness increased when the content of phosphor increased. The impact energy increased with increasing phosphor content at a temperature between 70 and $80{ }^{\circ} \mathrm{C}$ and the impact energy at 6 and $8 \mathrm{pH}$ was higher than at $9 \mathrm{pH}$. Martin et.al [11] studied the electroless plating of Ni-P with low content of phosphor on the substrate of magnesium alloy. Specimen's dimensions were $(20 \times 20 \times 1.6 \mathrm{~mm})$. The results showed uniform thin plating with $10 \mu \mathrm{m}$ thickness on the substrate at $60 \mathrm{~min}$ by $95.6 \% \mathrm{Ni}$ and $4.4 \% \mathrm{P}$ concentration. On the other hand, when the time of deposition increased to $180 \mathrm{~min}$ the thickness of plating reached to $30 \mu \mathrm{m}$. The hardness values have highly increased from 410 to $610 \mathrm{HV}$. Several examinations showed high resistance to corrosion by $0.1 \% \mathrm{M} \mathrm{NaCl}$ which carried out by Tafel test. The values $\boldsymbol{i}_{\text {corr }}$, for magnesium alloy and Ni-Pplating material, were 23.7 and $0.4 \mathrm{~A} / \mathrm{cm}^{2}$, respectively. SEM was conducted to know the morphology of surface after electroless plating which showed that no micro-cavities. Eman et.al [12] studied the electroless plating of Ni-P carbon steel specimens, the bath composition of electroless plating was nickel sulfate $15 \mathrm{~g} / \mathrm{L}$, sodium hypophosphite $30 \mathrm{~g} / \mathrm{L}$, lactic acid $20 \mathrm{~g} / \mathrm{L}$, citric acid $20 \mathrm{~g} / \mathrm{L}$.Several tests were carried out in this study, microhardness, XRD, SEM, thickness of coating, and Tafel analysis. The results showed that the micro-hardness increased from $160 \mathrm{HV}_{200}$ for substrate to $406 \mathrm{HV}_{200}$ after plating.
XRD analysis showed the presence of $\mathrm{Ni}_{3} \mathrm{P}$ on the surface of specimens. Tafel results in $3.5 \% \mathrm{NaCl}$ were 21.4 and $1.84 \mu \mathrm{A} / \mathrm{cm}^{2}$ for substrate and coating specimens by Ni-P respectively.

\section{Experimental details}

In this study, the metallic sheets of Inconel 600 alloy with dimensions (20 x $20 \times 2 \mathrm{~mm})$ with middle hole $(2 \mathrm{~mm})$ from the top are used for Ni-P coating. The chemical composition of the substrate was carried out by SPECTRO model (SPECTROMAXx) at General Company for Inspection and Engineering Rehabilitation-Baghdad. The result of chemical composition are presented in Table 1 . These sheets of specimens were flattened by using SiC grinding papers $(180,220,320,400,600,800,1000$, $1200,1500,2000,2500$ grit size). The specimens were cleaned by acetone in ultrasonic advice for 30 minutes to remove finishing compound, dust, and contaminations according to ASTM-B558, standard practice for preparation of nickel alloys. Later, the specimens were rinsed by distilled water and dried by an electrical dryer. Alkaline cleaning solution (60\% $\mathrm{NaOH}+38 \%$ Sodium Phosphate $+38 \%$ Sodium Carbonate) was used to remove the traces of grease, oil, or any contaminations at $65-70{ }^{\circ} \mathrm{C}$ with $3 \mathrm{~V}$ DC power supply. High activation of specimen's surface was applied to remove the thin film of oxide metal and to increase the adhesion between the surface and the plating. This process is carried out by nickel strike in electrolytic solution includes $\left(240 \mathrm{~g} / \mathrm{L} \mathrm{NiCl}_{2}\right.$ and $\left.250 \mathrm{ml} / \mathrm{L} \mathrm{HCl}\right)$ with $3 \mathrm{~V}$ DC power supply at temperature room and then the specimens were rinsed by distilled water and dried by electrical dryer. Table 2 presents compositions of bath solutions and operating conditions for electroless $\mathrm{Ni}-$ $\mathrm{P}$. In Ni-P bath, the sodium hypophosphite was used as a reducing agent. In addition, lactic acid and citric acid were added as a complexing agent and buffering agent respectively. The source of ion nickel was nickelsulfate. The process of coating is illustrated in Figure 1. The coating thickness was measured by using SEM through a cross section of coated specimens. In this study, the coating time of Ni-P was (2 and 3 hrs.) respectively. An energy dispersive spectroscopy (EDS) was used to analyze the coating compositions. The corrosion rates of the coating specimens in the $1 \mathrm{M} \mathrm{HCl}$ and $1 \mathrm{M} \mathrm{H}_{2} \mathrm{SO}_{4}$ solutions were measured by Tafel extrapolation. The morphology of Ni-P alloy was observed by using a scanning electron microscopy (VEGA III) analyzer. The hardness was measured at $25 \mathrm{~g}$ load and 15 s hold time by machine type (HVS-1000) tester.

Table 1. Substrate chemical composition.

\begin{tabular}{lllllll}
\hline Type & C & Mn & Si & Ni & Cr & Fe \\
\hline Wt.\% & 0.14 & 0.211 & 0.53 & 76.5 & 18.5 & 2.77 \\
Type & S & Ti & Mo & Cu & $\mathrm{Al}$ & \\
Wt. $\%$ & 0.01 & 0.38 & 0.16 & 0.01 & 0.234 & \\
\hline
\end{tabular}

Table 2. Operating Conditions and Bath composition of Ni-P [12]

\begin{tabular}{ll}
\hline Chemical Composition & Concentration $(\mathbf{g} / \mathbf{L})$ \\
\hline Nickel Sulfate & 15 \\
Sodium Hypophosphite & 30 \\
Lactic Acid & 20 \\
Citric Acid & 20 \\
Operating conditions & \\
pH & $4-6$ \\
Temperature & $85-90^{\circ} \mathrm{C}$ \\
Magnetic stirring (rpm) & $200 \pm 25$ \\
\hline
\end{tabular}




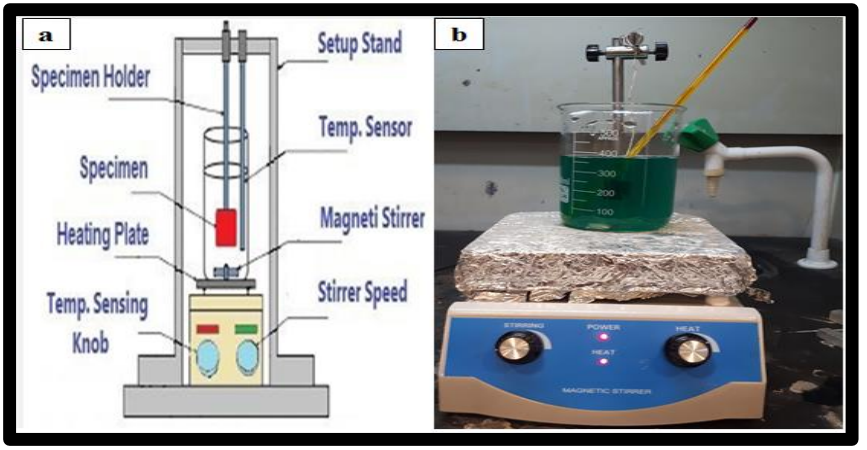

Figure 1. (a): Sketch of Electroless Plating Apparatus (b): The Actual Electroless Plating

\section{Results and discussion}

\subsection{Characterization of coatings}

\subsubsection{SEM images}

The surface morphology of the alloys deposited by EN process was shown in Figure 2. The Ni-P coating was successfully deposited on nickel base substrate.

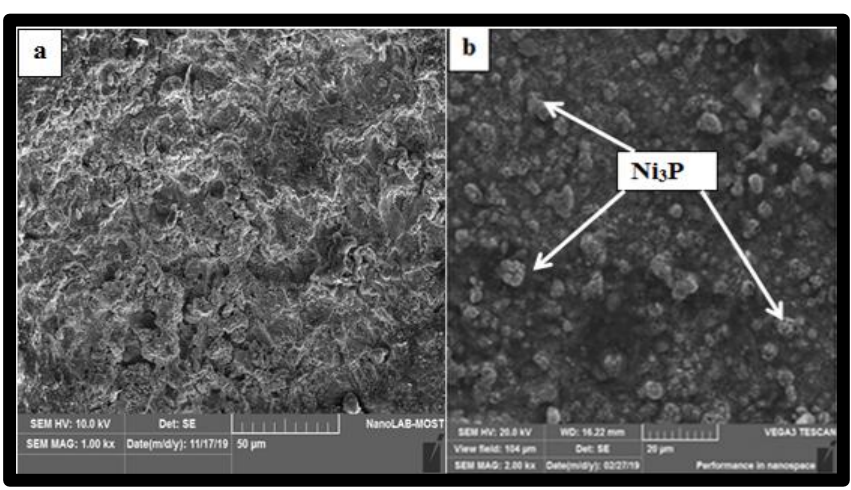

Figure 2 (a) and (b): SEM Images Show Surface Morphologies of NiP plating

The composition of coating at two different coating times ( 2 and $3 \mathrm{hr}$ ) and EDS analysis were shown in Figures 3 and 4, respectively. The deposits are mainly consisting of $\mathrm{Ni}$ and $\mathrm{P}$ elements.

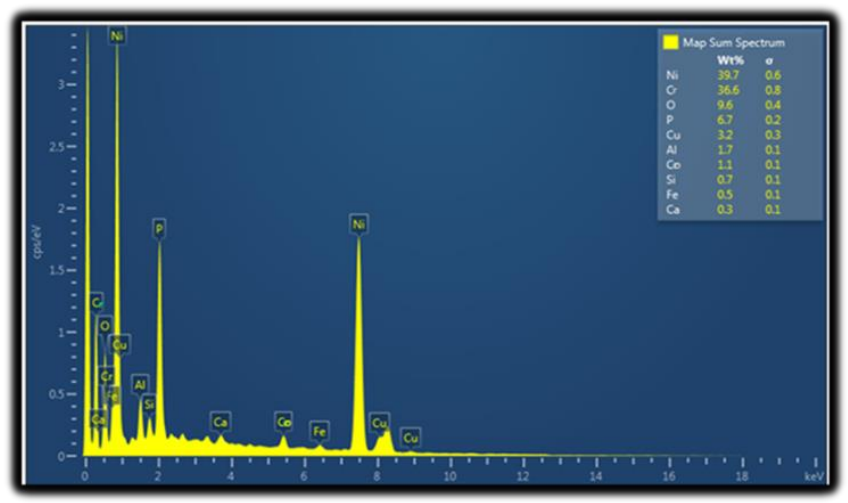

Figure 3. EDS Chart to Coated Specimen at 2 hr, coating time

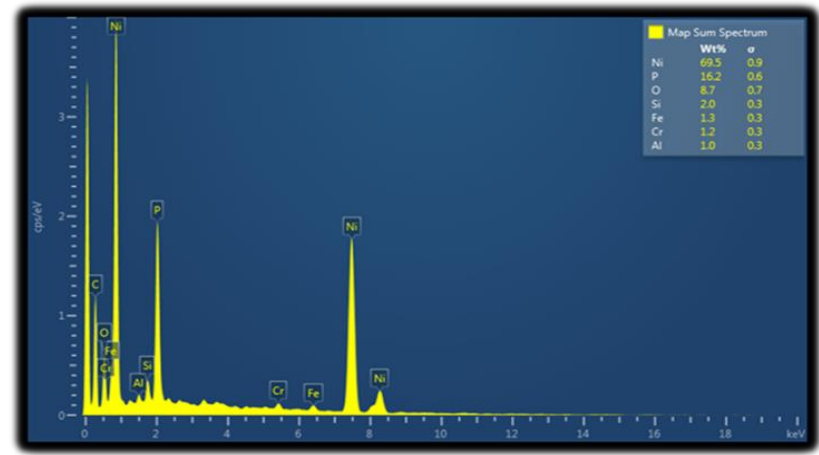

Figure 4. EDS Chart to Coated Specimen at 3hrs. Time of Coating

Figure 5 displays the cross-section morphology of as-plated Ni-P coating was checked by using SEM. It was revealed that the Ni-P coating thickness at $2 \mathrm{hrs}$. The time of coating is approximately $68.43 \mu \mathrm{m}$, whereas the coating of Ni-P at $3 \mathrm{hrs}$ time of coating has a thickness of $92.71 \mu \mathrm{m}$. This referring that the increase in the coating time increased the deposition rate. As well as, there are no cracks or defects observed at the interface of substratecoating. This proves a good adhesion for the coatings in $2 \mathrm{hrs}$. But some micro-cracks or pores have been noticed in high coating thickness which was resulted in high coating time (3hrs.).
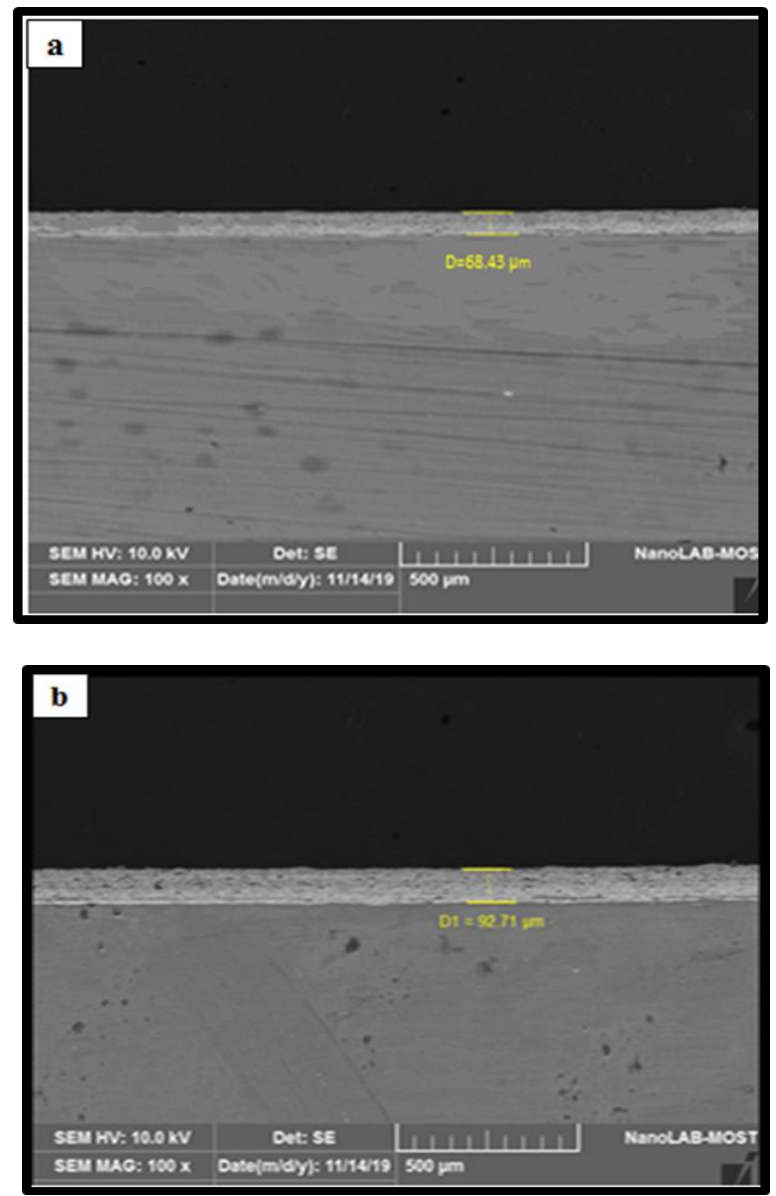

Figure 5. Coating Thickness in SEM image for Coating Specimens at: (a) $2 \mathrm{hr}$, and (b) $3 \mathrm{hrs,} \mathrm{coating} \mathrm{time}$ 


\subsubsection{Structures of the Ni-P Coating}

Figures 6 and 7 illustrate the XRD patterns for both the plated Ni-P coatings and the heat-treated Ni-P coatings, respectively. X-ray-diffraction analysis was used to identify all phases present in the specimens. The crystalline planes and their orientation for the phases were also analyzed. It is clear in Figure 6, the presence of $\mathrm{NiP}$ and $\mathrm{Ni}_{5} \mathrm{P}_{2}$ in the coating layer. The major phase is $\mathrm{NiP}$ due to more scattering of $\mathrm{X}$-ray through this phase in the plane of (311) in 17 present. However, the (424) plane of $\mathrm{Ni}_{5} \mathrm{P}_{2}$ is scattered of $\mathrm{X}$ ray with 45 present.

On the other hand, Figure 7 shows the X-ray diffraction pattern for Ni-P plating bath after heat treatment. It is clear that the presence of $\mathrm{Ni}_{3} \mathrm{P}$ in the coating layer which considers the major phase, so it more scattering of $\mathrm{X}$ ray through this phase in the plane (233). In most of electroless plating by $\mathrm{Ni}-\mathrm{P}$, the presence of the intermetallic compound especially the $\left(\mathrm{Ni}_{3} \mathrm{P}\right)$ is necessary to improve most of the mechanical properties such as corrosion resistance and hardness.

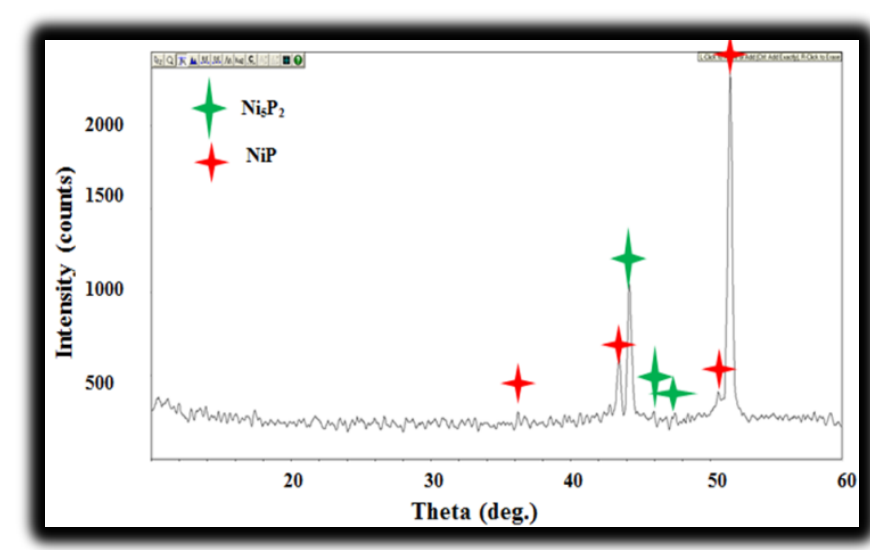

Figure 6: XRD Pattern of Electroless Plating as Plated

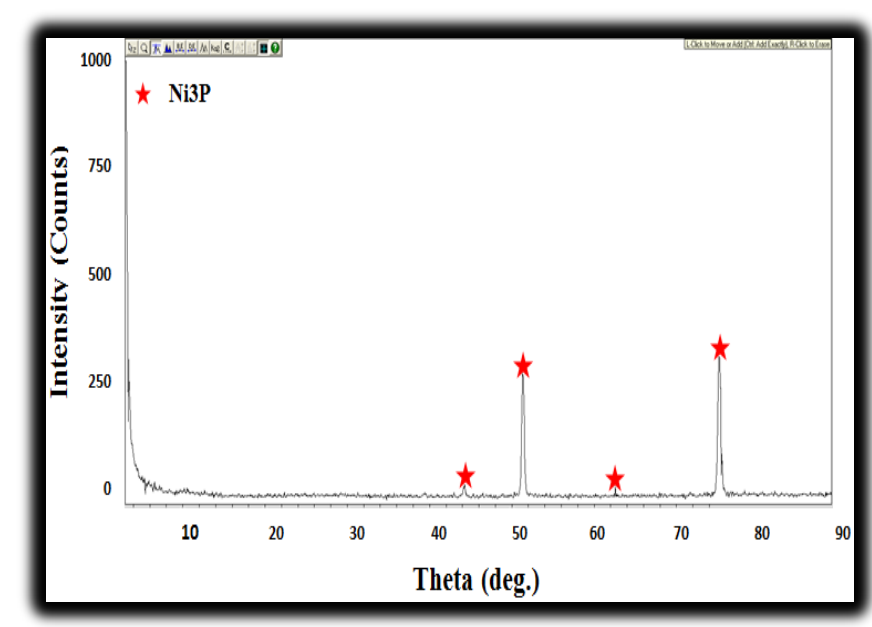

Figure 7: XRD Pattern of Electroless Plating after Heat Treated

\subsection{Micro-hardness Measurements}

Micro-hardness of the Ni-P coatings before and after a heat treatment were performed and compared with the Inconel 600 alloy substrate, and displayed in Figure 8. The micro-hardness value of the substrate was approximately $270 \mathrm{HV}_{200}$. The electroless plating of the Ni-P after heat treatment leads to an increase in the micro-hardness to 516 and $401.5 \mathrm{HV}$ at 2 and 3 hrs time of coating, respectively. The increase in the hardness values is due to the formation of intermetallic compounds such as $\mathrm{Ni}_{3} \mathrm{P}$, $\mathrm{Ni}_{5} \mathrm{P}_{2}$, and $\mathrm{NiP}$ or any similar intermetallic compound, having a chemical formula of $\mathrm{Ni}_{X} \mathrm{P}_{Y}$.All these intermetallic compounds have high resistance to penetration (hardness).

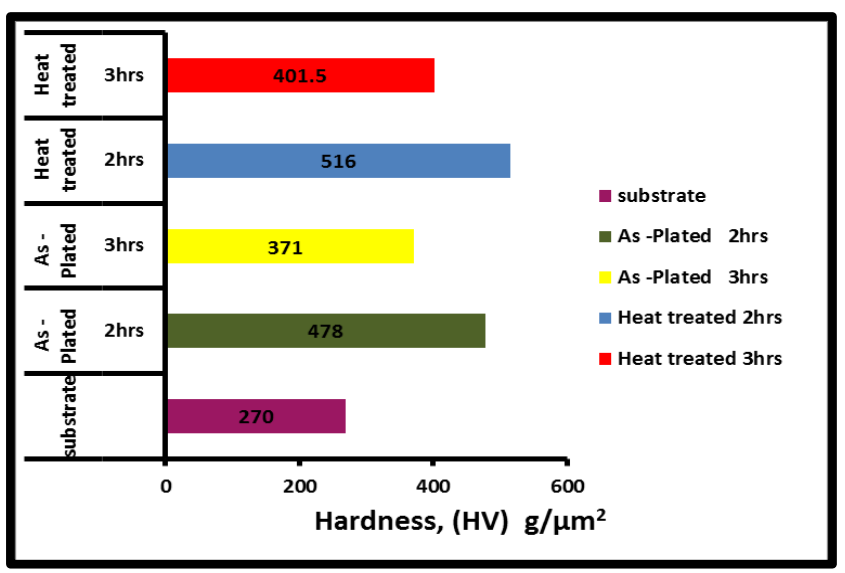

Figure 8: The Micro-hardness of Substrate, Ni-P Plating, before and after heat treatment at $400{ }^{\circ} \mathrm{C}$ for $1 \mathrm{~h}$.

\subsection{Corrosion Measurements}

\subsubsection{Tafel Analysis}

The polarization curves for electroless Ni-P and the substrate in $1 \mathrm{M} \mathrm{HCl}$ and $1 \mathrm{M} \mathrm{H}_{2} \mathrm{SO}_{4}$ solutions at temperature room are illustrated in Figures 9 to 13. The parameters of electrochemical (corrosion current density $\left(\mathrm{i}_{\text {corr }}\right)$ and corrosion potential $\left(\mathrm{E}_{\text {corr }}\right)$ corrosions, anodic and cathodic Tafel slopes, are presented in Table 2. The highest $\mathrm{i}_{\text {corr }}$ occurred in bare specimens through $\left(1 \mathrm{M} \mathrm{H}_{2} \mathrm{SO}_{4}\right)$ and $(1 \mathrm{M} \mathrm{HCl})$ solutions where it reached 42.235 and 27.525 $\mu \mathrm{A} / \mathrm{cm}^{2}$, respectively. The current density ( $\mathrm{i}_{\text {corr }}$ ) for coated specimens by Ni$\mathrm{P}$ has lower corrosion density than that for the bare specimens, and consequently the Ni-P plating has high resistivity. The high thickness of specimens due to long coating time has lower corrosion current density $\left(i_{\text {corr }}\right)$ than the specimens with less time of coating.

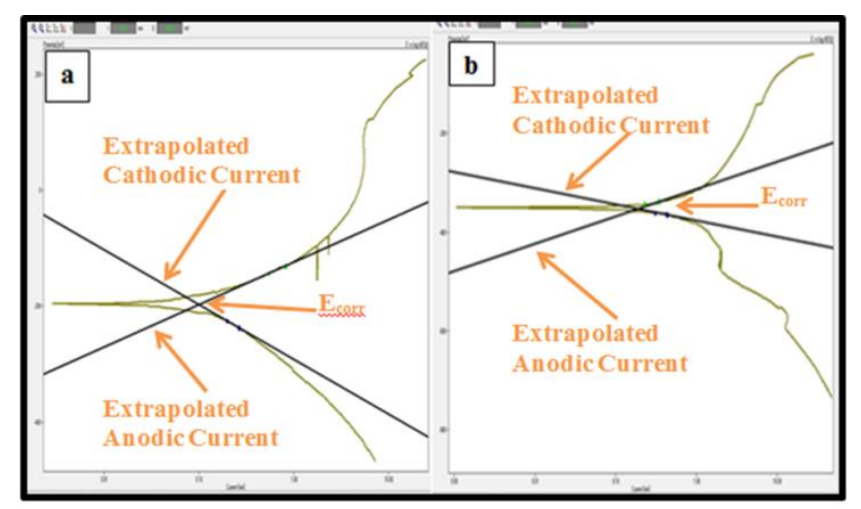

Figure 9: Polarization Curve for Bare Specimen in (a): (1M HCI) (b): (1M H2SO4) 


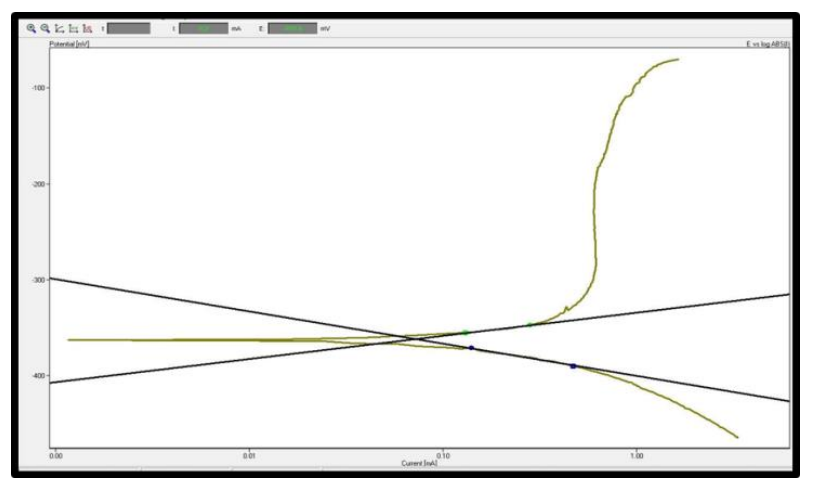

Figure 10: Polarization Curve for Coated Specimen by Ni-P with 2hrs.Time of Coating in $\left(\mathrm{MM} \mathrm{H}_{2} \mathrm{SO}_{4}\right)$

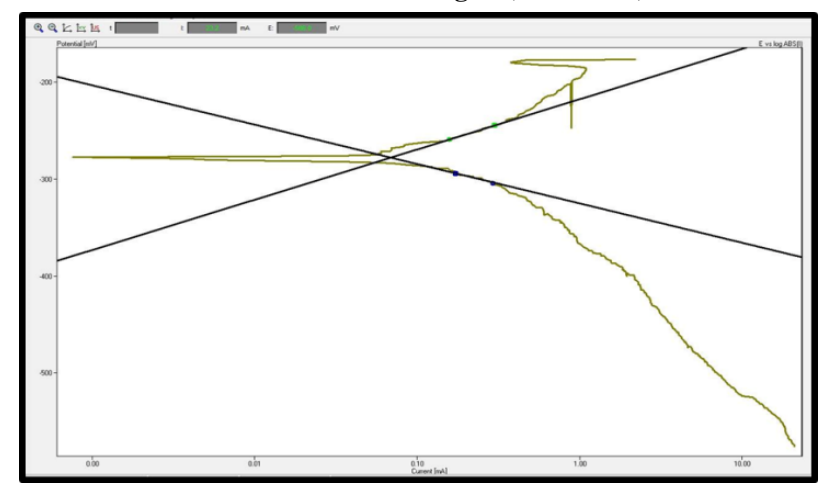

Figure 11: Polarization Curve for Coated Specimen by Ni-P with 2hrs. Time of Coating in (1M HCl)

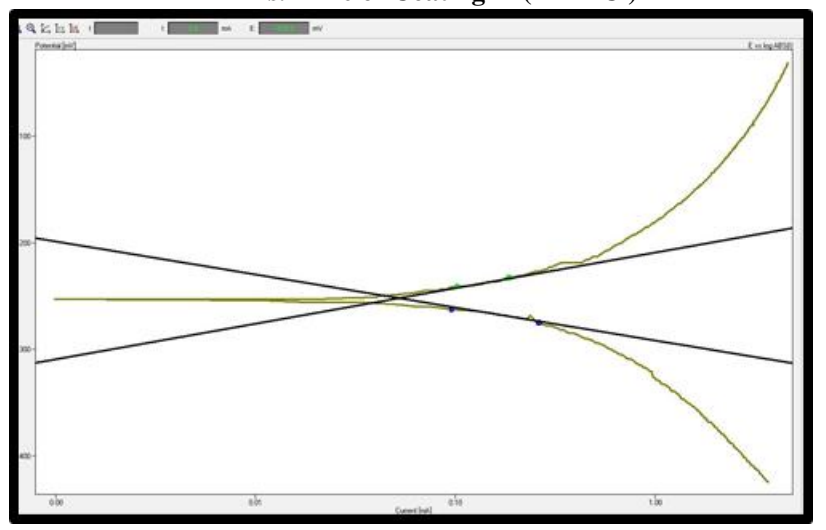

Figure 12: Polarization Curve for Coated Specimen by Ni-P with 3hrs. Time of Coating in $\left(\mathrm{MM} \mathrm{H}_{2} \mathrm{SO}_{4}\right)$

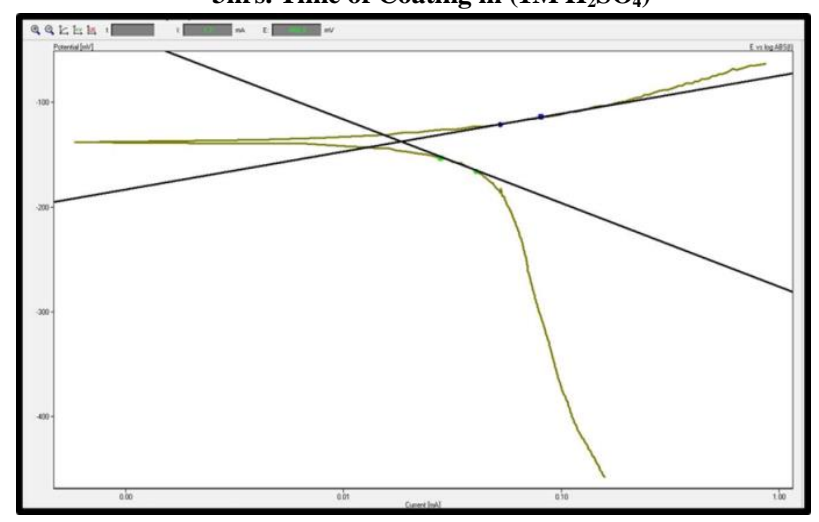

Figure 13: Polarization Curve for Coated Specimen by Ni-P with 3hrs. Time of Coating in (1M HCl)
Table 3: Corrosion Parameters for Polarization of Bare and Coated Specimens

\begin{tabular}{|c|c|c|c|c|}
\hline \multicolumn{5}{|c|}{ Polarization Results in $1 \mathrm{M} \mathrm{H}_{2} \mathrm{SO}_{4}$} \\
\hline Specimens & $\mathbf{E}_{\text {corr }}(\mathbf{m V})$ & $\mathbf{I}_{\text {corr }}(\boldsymbol{\mu} \mathbf{A})$ & $\operatorname{orr}\left(\boldsymbol{\mu} \mathrm{A} / \mathbf{m m}^{2}\right)$ & $\begin{array}{l}\text { Corrosion } \\
\text { rate (mpy) }\end{array}$ \\
\hline Bare Specimen & -352.8 & 168.94 & 42.235 & 17.201 \\
\hline $\begin{array}{l}\text { Coated Specimen } \\
\text { by Ni-P for } 2 \text {-hrs. }\end{array}$ & -361.8 & 72.27 & 18.067 & 5.155 \\
\hline $\begin{array}{l}\text { Coated Specimen } \\
\text { by Ni-P for 3-hrs. }\end{array}$ & -252.1 & 52.27 & 13.068 & 3.24 \\
\hline \multicolumn{5}{|c|}{ Polarization Results in $1 \mathrm{M} \mathrm{HCl}$} \\
\hline Bare Specimen & -195 & 110.1 & 27.525 & 11.210 \\
\hline $\begin{array}{l}\text { Coated Specimen } \\
\text { by Ni-P for 2-hrs. }\end{array}$ & -277.7 & 68.83 & 17.207 & 4.910 \\
\hline $\begin{array}{l}\text { Coated Specimen } \\
\text { by Ni-P for 3-hrs. }\end{array}$ & -137.5 & 18.42 & 4.605 & 1.144 \\
\hline
\end{tabular}

\section{Conclusions}

The electroless plating by Ni-P is an effective method in the coating of metal or alloys that can provide an acceptable homogenous distribution in most metals and alloys substrates. The morphology, structure, microhardness, and corrosion resistance of the electroless Ni-P plating showed better properties compared to these for the bare specimens. The structure of the as-deposited Ni-P plating was amorphous, while it was crystalline for the heat-treated specimens. The coating thickness of the specimens at 2 and $3 \mathrm{hrs}$ coating time has a range between $(51-70)$ and $(71-95 \mu \mathrm{m})$ respectively. The better surface and mechanical properties were obtained in the range of thickness $(51-70 \mu \mathrm{m})$. The thicker coating had more pores and cracks when comparison with lower thickness coating. The Vickers hardness of the coated specimens at $2 \mathrm{hr}$ coating time increased by $47 \%$ when compared with the bare specimens. On the other hand the microhardness for the coated specimens at $3 \mathrm{hrs}$ coating time increased by $32 \%$ when compared with the bare specimens. Tafel analysis showed a superior corrosion resistance for the coated specimens at 3 hrs coating time when compared with the bare specimens.

\section{REFERENCES}

[1] M. Palaniappa, S. K. Seshadri, Structural and Phase Transformation Behaviour of Electroless Ni-P and Ni-W-P Deposits,Materials Science and Engineering: A, 460 (2007) 638-644.

[2] Z.Yin, F. Chen, Effect of Nickel Immersion Pretreatment on The Corrosion Performance of Electroless Deposited Ni-P Alloys on Aluminum, Surface and Coatings Technology, 228 (2013) 34-40.

[3] J. Sudagar, J. Lian, W. Sha, Electroless Nickel, Alloy, Composite and Nano Coatings-A critical Review, Journal of Alloys and Compounds,. 571 (2013) 183-204.

[4] R. Parkinson, Properties and Applications of Electroless Nickel, Nickel Development Institute, 37(1997) 1-33.

[5] P. Gadhari, P. Sahoo, Study of Tribological Properties of Electroless $\mathrm{Ni}-\mathrm{P}-\mathrm{Al}_{2} \mathrm{O}_{3}$ Composite Coatings, IOSR Journal of Mechanical and Civil Engineering, 1 (2014) 34-37

[6] R. N. Duncan, Electroless Nickel: Past, Present and Future, Electroless Nickel , 93(1993), Conference, Orlando

[7] M. S. Yeh, C. B., Chang, T. H. Chuang, Diffusion Bonding of A superplastic Inconel 718SPF Superalloy by Electroless Nickel Plating, Journal of Materials Engineering and Performance, 9 (1) (2000)51-55.

[8] C. O. Osifuye, A. P. I., Popoola, C. A., Loto, D. T. Oloruntoba, Effect of Bath Parameters on Electroless Ni-P and Zn-P Deposition on 1045 Steel Substrate, Journal of Electrochemical Science, Vol. 9(2014)6074-6087. 
[9] E.S. Jburi, Electroless Ni-P Coating on The Medium Carbon Steel, MSC Thesis, University of Babylon, Iraq, 2016.

[10] D. K. Basavaraja, Skanda, M. G., Soumya, V. Ramesh, Experimental Investigation on The Effects of Electroless Nickel Phosphorus Deposition, $\mathrm{pH}$ and Temperature with The Varying Coating Bath Parameters on Impact Energy by Taguchi Method, Int J Mech, Aerosp, Ind, Mechatron Manuf. Eng, 11 (4) (2017) 698-704

[11] M. Buchtík, P. K. Jaromír, W.J. Tkacz Characterization of Electroless Ni-P Coating Prepared on a Wrought ZE10 Magnesium Alloy, Coatings, 8 (96)(2018) 1-14.

[12] E. Fayyad, A.Abdullah, , M. Hassan, A.Mohamed, C. Wang, G.Jarjoura, Z. Farhat, Characterization, and Application of Novel Ni-P-Carbon Nitride Nanocomposites, Coatings, 8 (1)(2018),. 37. 